\title{
Analysis of Laser Welds on Steel Processed by Q-P Process
}

\author{
Ivan Vorel, Kateřina Rubešová, Omid Khalaj, Kateřina Opatová, Martin Franz-Xaver Wagner
}

\begin{abstract}
The use of new advanced high-strength (AHSS) steels is often constrained by the state of the art in related processing and fabrication technologies. These technologies are only beginning to encounter the requirements that these advanced materials bring. Typical examples are joining and, in particular, welding. The latter has a major effect on microstructure evolution and, in turn, on mechanical properties. A common concern is that welding is not at all suitable as the joining technique for a particular application. This is why an experiment has been carried out which involves laser welding of a high-strength Q-P-processed AHS steel. Its results suggest that, by combining these technologies, very good results can be achieved, particularly in components under dynamic loading.
\end{abstract} Q-P.

Keywords - AHSS, Laser welding, Mechanical properties,

\section{Introduction}

Novel materials, including AHS steels, gradually put pressure on technologies used in processing and fabrication. These technologies include heat treatment and thermomechanical processing and joining techniques, including welding. The evolution of advanced steel processing technologies has led to strengths of about $2000 \mathrm{MPa}$ and elongation levels of $10 \%$ in steels with cost-

Ing. Ivan Vorel

University of West Bohemia

Czech Republic

Kateřina Rubešová

University of West Bohemia

Czech Republic

Dr. Omid Khalaj

University of West Bohemia

Czech Republic

Kateřina Opatová

University of West Bohemia

Czech Republic

Univ.- Prof. Dr.- Ing. habil. Martin Franz-Xaver Wagner

Technische Universität Chemnitz

Germany effective alloying. This was thanks to the complex multiphase microstructure of these steels. One of those microstructures is represented by the mixture of martensite and austenite and can be obtained by incomplete quenching and partitioning, known as the Q-P process [1]. The process is characterized by quenching from the austenite region to the region between martensite-start temperature $\left(\mathrm{M}_{\mathrm{s}}\right)$ and martensite-finish temperature $\left(\mathrm{M}_{\mathrm{f}}\right)$ [2,3]. There, just above the $\mathrm{M}_{\mathrm{f}}$, the cooling is interrupted. Consequently, martensitic transformation does not take place in the entire volume and some amount of austenite is retained [4]. This metastable austenite is typically found in the form of thin layers on the boundaries of martensite needles. However, it may also be present in other locations. Martensite imparts high strength to steel. Under normal conditions, however, it is too brittle and undesirable in parts intended for normal use and, in particular, parts operating under dynamic loading. This drawback can be eliminated by having an appropriate amount of austenite in the microstructure. Normally, the proportion is approximately $10 \%$ but the amount of austenite may reach up to $20 \%$. Austenite has good plasticity. If distributed appropriately in the microstructure, it reduces the stress between martensite needles. Thanks to the plasticity of austenite, steel can be worked without suffering brittle failure, which is otherwise characteristic of martensite. For these reasons, metastable austenite must be retained upon cooling to ambient temperature and must not transform to martensite: this means it must be stabilized [5]. Saturation with carbon can provide this stabilization. Holding for several minutes at an elevated temperature causes a portion of the carbon atoms to diffuse from the martensite into the austenite. This stabilizes the austenite and relieves the stress in the martensite. A material with this microstructure exhibits excellent mechanical properties, including fatigue strength of more than $2000 \mathrm{MPa}$ [6].

\section{Experimental}

The objective of the present experiment was to explore whether Q-P-processed high-strength steels can be welded successfully. Specimens of $2.5-\mathrm{mm}$ metal sheet of $42 \mathrm{SiCr}$ steel were butt-welded by means of laser [7]. The metallographic analysis and hardness measurement was performed across the weld (Fig. 1). The proportion of retained austenite in the matrix was $10 \%$. To ensure that the test only reflects the effect of the welding process on the microstructural evolution and properties, the welded pieces were ground on both surfaces, so that stress concentrators were removed. The specimens had a gauge length of $5 \mathrm{~mm}$ and a cross-section of $1.2 \times 2 \mathrm{~mm}$. These specimens were used for tensile testing at various strain rates between $10^{-3} \mathrm{~s}^{-1}$ and $101 \mathrm{~s}^{-1}$. 


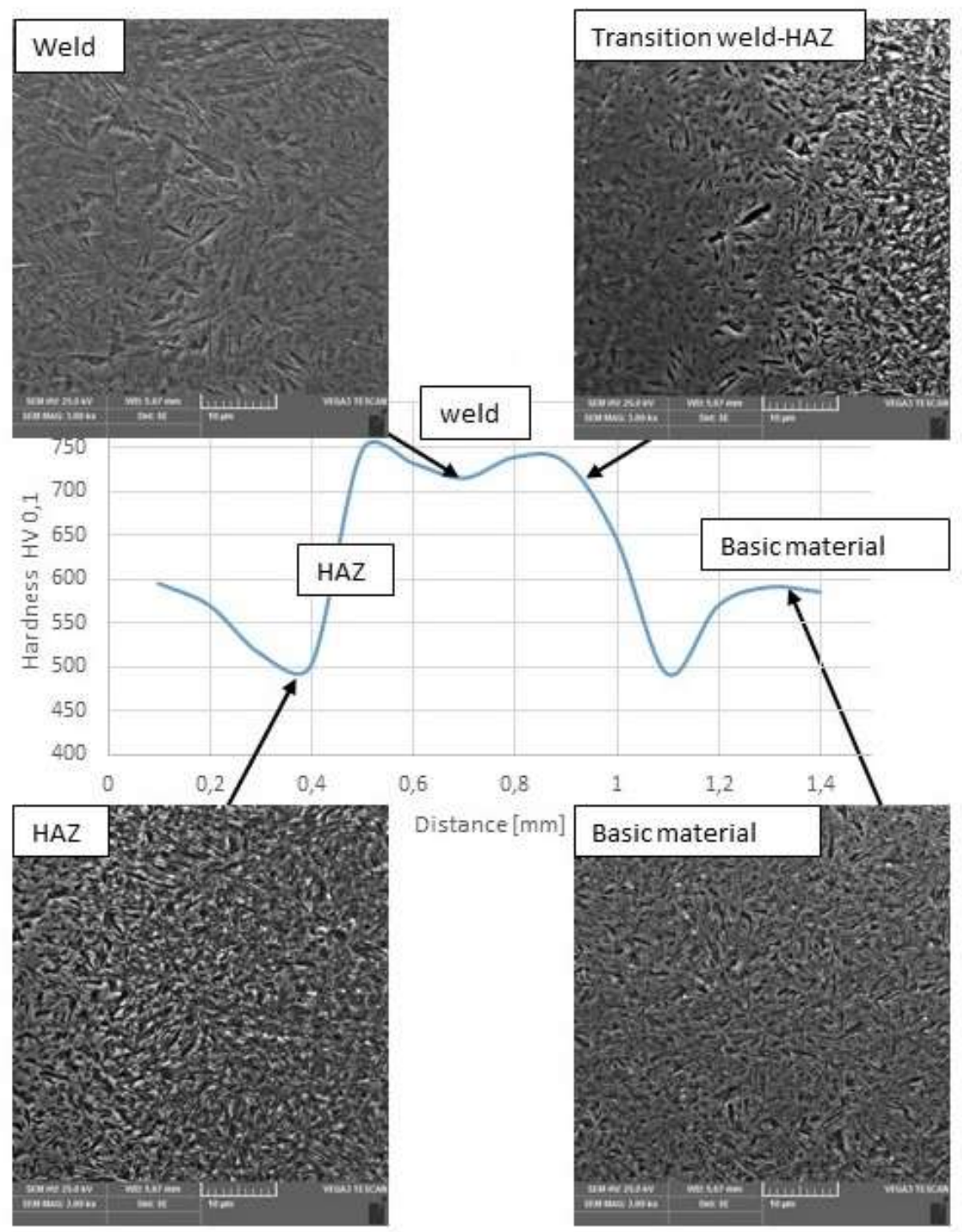

Figure 1 - The microstructures and hardness profile along the longitudinal axis of test specimen

\section{Results}

Microstructure had a martensitic character with stable retained austenite. Hardness profile range was from 500 to 750 HV0,1. Tensile testing showed that when a quasi-static load was applied, the failure occurred in the welded joint (Fig. 2). Despite this, the fracture was mostly ductile in nature. Only in some cases was there a minor proportion of brittle fracture (Fig. 3). $\mathrm{A}_{5 \mathrm{~mm}}$ elongation value was

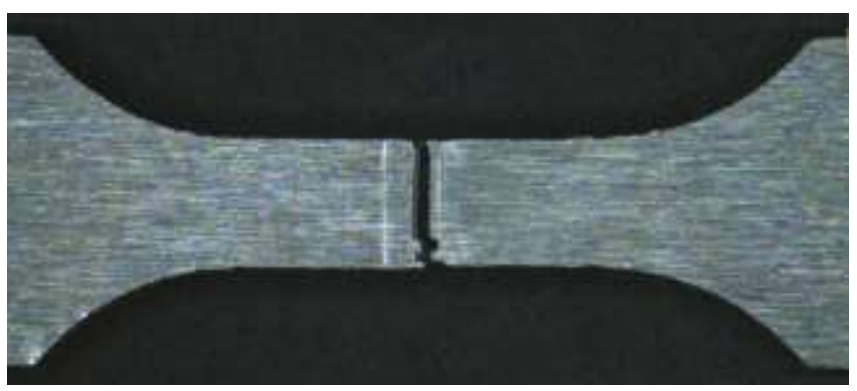

Figure 2 - Failure of welded joint under quasi-static load
Approximately $6 \%$. Ultimate strength was $1950 \mathrm{MPa}$ (Fig. 4). When strain rate was increased by between 3 and 4

orders of magnitude, the type of fracture profoundly changed. In all tests, the failure occurred outside the weld and outside the heat-affected zone (Fig. 5). The base material underwent plastic deformation and the reduction of its cross-section was visible. The fracture surface was exclusively ductile (Fig. 6). Ultimate strength was comparable to the value found by the static test, approximately $1950 \mathrm{MPa}$. The ductility of the material, however, led to twice as high elongation level: approximately $12 \%$.

\section{Conclusion}

The findings suggest that AHS steels can be welded using methods available today and that very good mechanical properties of welded joints can be achieved. In 
terms of the material per se, there is no obstacle to combining the Q-P process with laser welding in the processing of steels with $0.42 \%$ carbon. Naturally, another logical prerequisite for success is an accurate definition of ranges of welding processing parameters, within which excellent results can be achieved, while keeping the process robust. To fully clarify these phenomena, further research is necessary. One can assume that the new findings will allow the welding process to be effectively optimized in order to achieve excellent results in laser welds of AHSS steels with strengths of about $2000 \mathrm{MPa}$.

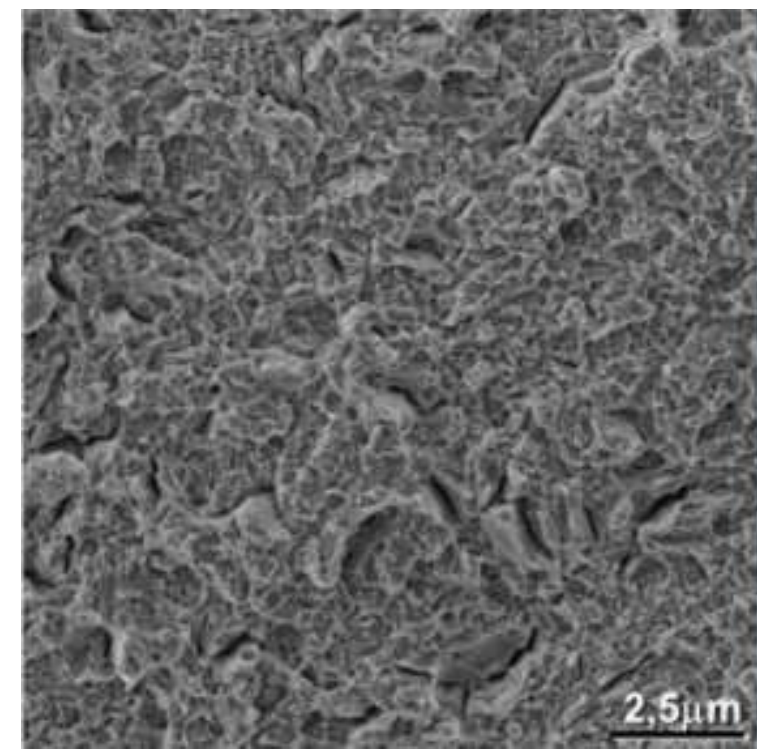

Figure 3 - Fracture surface within the weld with predominantly ductile fracture after a static tensile test

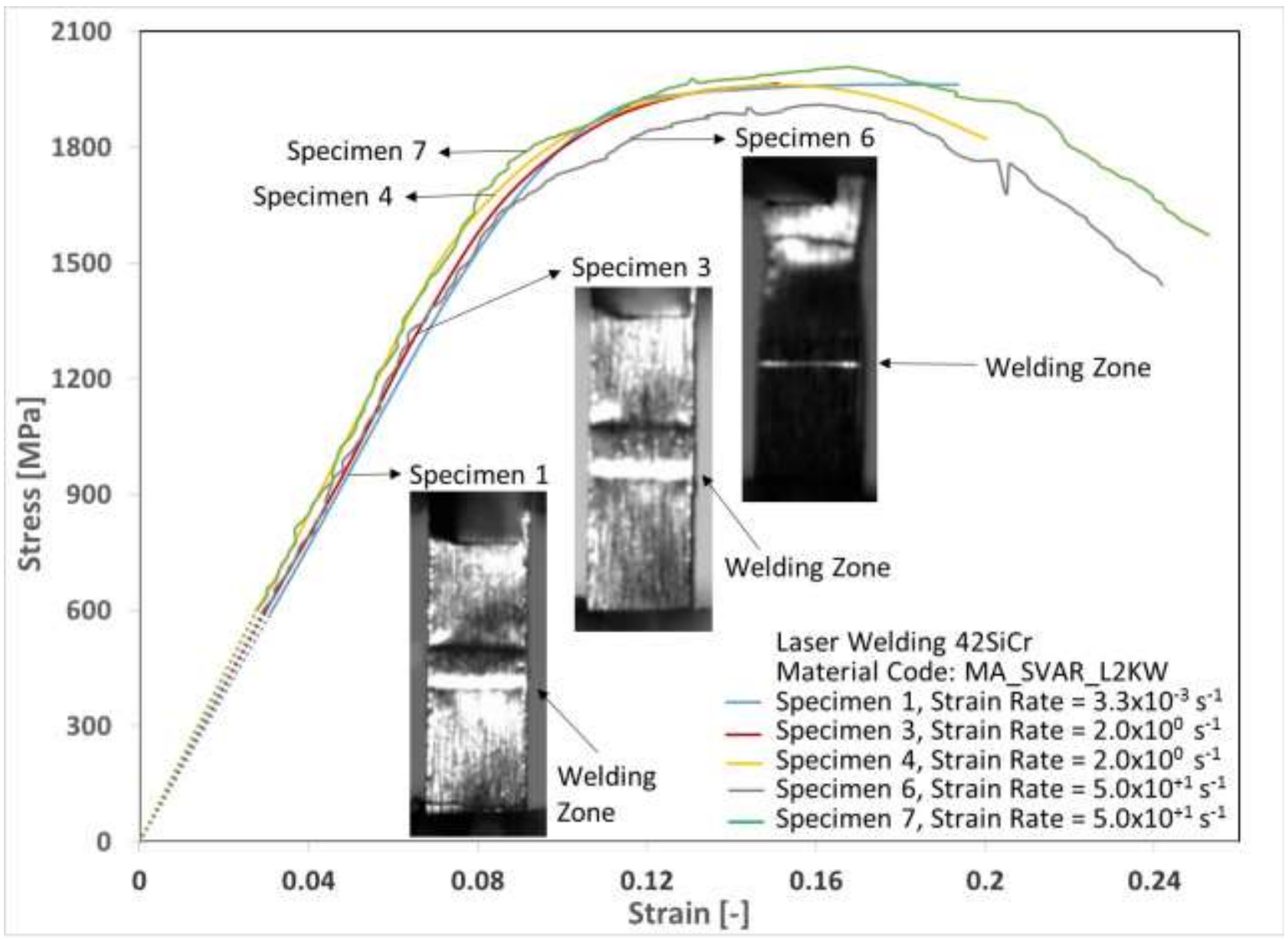

Figure 4 - Stress-strain curves for specimens with welds tested at various deformation rates 
Proc. of The Fourth Intl. Conf. On Advances in Mechanical, Aeronautical and Production Techniques - MAPT 2015 Copyright (C) Institute of Research Engineers and Doctors, USA .All rights reserved.

ISBN: 978-1-63248-072-9 doi: 10.15224/ 978-1-63248-072-9-56

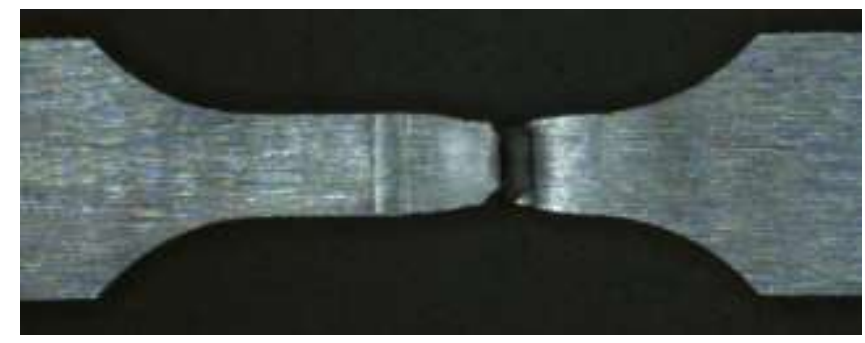

Figure 5 - Contraction of basic material outside the weld zone during the tensile test, position of the weld between the white lines

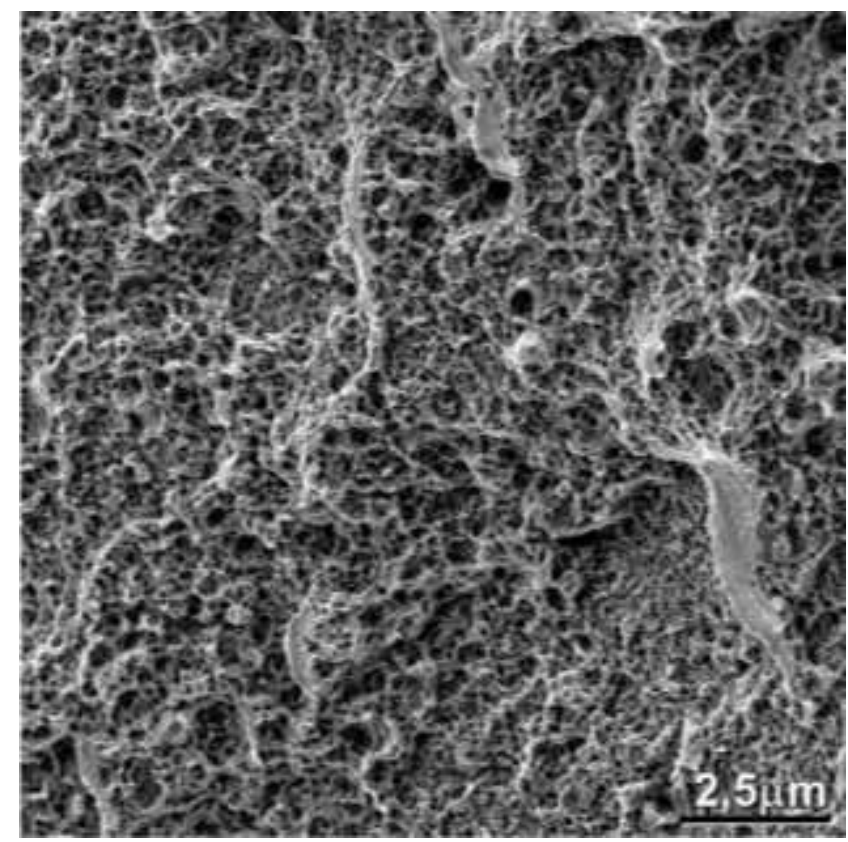

Figure 6 Fracture surface outside the weld and the heat - affected zone with ductile fracture after a dynamic tensile test

\section{Acknowledgment}

This paper includes results created within the projects LO1502 Development of Regional Technological Institute and CZ.1.05/3.1.00/14.0297 Technological Verification of R\&D Results II, individual activity Hollow Shafts for Passenger Cars Produced by Heat Treatment with the Integration of Q-P Process. The projects are subsidised by the Ministry of Education, Youth and Sports from resources of the state budget of the Czech Republic and European Regional Development Fund.

\section{References}

[1] D. V. Edmonds et al., "Quenching and partitioning martensite - A novel steel heat treatment", Materials Science and Engineering A, vol. 25, pp. 438-440, 2006.

[2] H. Jirková, L. Kučerová, B. Mašek, "Effect of Quenching and Partitioning Temperatures in the Q-P Process on the Properties of AHSS with Various Amounts of Manganese and Silicon," Materials Science Forum, vol. 706-709, pp. 2734-2739, 2012.

[3] B. Mašek, H. Jirková, D. Hauserová, L. Kučerová, D. Klauberová, "The Effect of Mn and Si on the Properties of Advanced High Strength Steels Processed by
Quenching and Partitioning," Materials Science Forum, vol. 654-656, pp. 94-97, 2010.

[4] E. De Moor, S. Lacroix, A. J. Clarke, J. Penning, J. G. Speer, "Effect of Retained Austenite Stabilized via Quench and Partitioning on the Strain Hardening of Martensitic Steels," Metallurgical and Materials Transactions A, vol. 39A, pp. 2586-2595, 2008.

[5] H. Jirková, L. Kučerová, "Q-P Process on Steels with Various Carbon and Chromium Contents," Proceedings of PRICM: 8 Pacific Rim International Congress on Advanced Materials and Processing Hoboken, pp. 819824, 2013.

[6] H. Jirková, B. Mašek, M. F.-X. Wagner, D. Langmajerová, L. Kučerová, R. Treml, D. Kiener, "Influence of Metastable Retained Austenite on Macro and Micromechanical Properties of Steel Processed by the Q\&P Process," Journal of Alloys and Compounds, vol. 615, pp. 163-168, 2014.

[7] L. Kučerová, H. Jirková, B. Mašek, "The Effect of Alloying on Mechanical Properties of Advanced High Strength Steels," Archives of Metallurgy and Materials, vol. 59, pp. 1189-1192, 2014.

About Author:

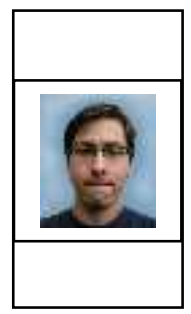

Ivan Vorel is the researcher focused on the development of high-strength steels and unconventional methods of production and processing of die forgings. 